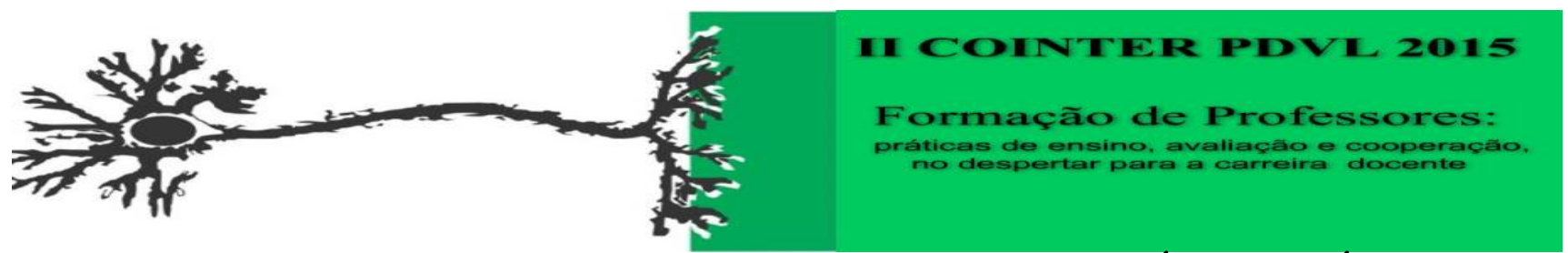

\title{
O USO DE AULAS EXPERIMENTAIS NO ENSINO DE CINÉTICA QUÍMICA
}

\author{
Apresentação: Comunicação Oral \\ Stephanie Silva Weigel Gomes ${ }^{1}$; Angelo Antonio Pereira dos Santos ${ }^{2}$; José Cícero da Silva Júnior ${ }^{3}$ \\ Johnnatan Duarte de Freitas ${ }^{4}$
}

\begin{abstract}
Resumo
Atualmente, a relação entre teoria e prática nas aulas de química vem se fazendo necessária, uma vez que esta é uma ferramenta eficiente que pode ser utilizada para despertar maior interesse do aluno pela disciplina e auxiliar em sua aprendizagem. Embora a maioria das escolas públicas tenham laboratórios de ensino de ciências a disposição dos professores, este ainda não é um recurso que é utilizado com frequência pelos próprios professores. Sendo assim, O presente trabalho teve como objetivo, buscar uma nova metodologia de ensino- aprendizagem para uma turma de $2^{\circ}$ ano do ensino médio de uma escola pública localizada no Estado de Maceió, Alagoas. A proposta sugerida foi apresentar uma metodologia diferente da utilizada em sala de aula pelo professor da disciplina. O trabalho surgiu como uma propsta de atividade da disciplina Projetos Integradores no Ensino de Química VI, do $6^{\circ}$ período do curso de Licenciatura em Química do Instituto Federal de Educação, Ciência e Tecnologia de Alagoas - Campus Maceió. A pesquisa é fundamentada nos textos de Evangelista (2007), Altet (2001), Brasil (1999), entre outros. A atividade foi escolhida como metodologia interdisciplinar de realização de aulas práticas que pudessem associar o assunto teórico que foi ensinado, com a prática e o cotidiano do aluno. Aproveitando a turma que era analisada por estagiários que cursavam a disciplina de estágio supervisionado II, foi montado um plano de aula onde fosse possível analisar o desempenho dos alunos nas aulas teóricas e depois nas aulas práticas. Após a realização das aulas foi possível concluir que, as aulas experimentais facilitam o aprendizado e despertam o interesse da maioria dos alunos, e se bem planejada, pode se tornar uma ferramenta didática que pode ser constantemente usada pelo professor de Química.
\end{abstract}

Palavras-Chave: Ensino de química. Aulas experimentais. Diferentes metodologias

\section{Introdução}

A química é a ciência que estuda a matéria, as transformações químicas por ela sofridas e as variações de energia que acompanham estas transformações. Por essa razão, experimentos se fazem necessários além de toda teoria que possa existir. Pois não há como se formular um conceito, sem que haja práticas experimentais. Vale também ressaltar que as grandes leis e teorias químicas surgiram através de experimentos que foram realizados estudados para então ser formulado um conceito.

\footnotetext{
${ }^{1}$ Licenciatura em Química, Instituto Federal de Alagoas, stephanie_weigel@hotmail.com

${ }^{2}$ Licenciatura em Química, Instituto Federal de Alagoas, aspirante.a.oficial.junior@hotmail.com

${ }^{3}$ Licenciatura em Química, Instituto Federal de Alagoas,olegna.angelo@hotmail.com

${ }^{4}$ Doutor em Química Orgânica, Instituto Federal de Alagoas, johnnatandf@gmail.com
} 
Sabemos que a química está presente em inúmeras situações de nosso cotidiano, e uma das habilidades fundamentais de um professor de química nos tempos atuais é saber mostrar ao aluno a relação entre todo conteúdo ensinado em sala de aula, com seu dia a dia.

Aulas experimentais também se fazem necessárias no ensino médio, pois essa é mais uma ferramenta que pode ser usada para facilitar a aprendizagem dos alunos e despertar um possível interesse pela disciplina.

Muitos autores discutem sobre aulas práticas e de como é importante sua realização no ensino médio para que haja uma melhoria no processo de ensino-aprendizagem. Nesse sentido, é possível observar que em muitos espaços de ensino formais os professores têm buscado meios que possibilitem aulas cada vez mais dinâmicas e dialéticas, fugindo das características adotadas desde o tempo do Império, uma educação de caráter tradicional e mecânica.

\section{Fundamentação Teórica}

A compreensão inadequada de como se devem dar as relações entre teoria e prática traz como consequências o famoso gesto de "pedir receitas". A cada novidade que se divulga, os professores se perguntam "como fazer", ao invés de, eles próprios, descobrirem os caminhos de apropriação das teorias para orientar as práticas. E isso é respaldado, em larga escala, pelas concepções e pelos significados que costumam ser atribuídos aos termos envolvidos, os quais assentam a relação entre teoria e prática no domínio conceitual da oposição e não da integração.

Ou seja, o que se apresenta como formas de aulas práticas em contra posição aos métodos teóricos não é apenas a busca por aulas práticas, e sim, uma inovação em relação ao que já existe, não basta uma mera cópia do que já está posto. Mas sim, a busca incessante por formas que possam ser enquadradas a realidade de cada sala de aula.

Mesmo esse sendo um tema bastante discutido entre os alunos de licenciatura atualmente, essa ainda não é uma realidade encontrada em diversas escolas:

Poucas escolas do ensino médio ministram aulas de química enfatizando a parte prática, apesar de se construir numa ciência essencialmente experimental. $\mathrm{O}$ baixo rendimento dos alunos de química nesse nível de ensino em todo o país é um fato e não há quem desconheça isto. As causas frequentemente apontadas como responsáveis por esta situação desconfortável e aflitiva são atribuídas ao preparo profissional deficientes, à falta de oportunidade para o professor se atualizar, aos salários baixos e à deficiência das condições materiais na maioria das escolas (EVAGELISTA, 2007). 
Investigar, portanto, as expectativas e eficácia que os estudantes apresentam sobre as aulas experimentais em relação ao aprendizado é um exercício de investigação que acaba não se esgotando nele próprio. Isso porque, com base nestas tais expectativas é possível compreender muitos fenômenos e representações sociais ligadas ao universo estudantil.

Levando em consideração o ensino básico e suas especificidades, é possível observar as marcas que os estudantes carregam consigo em função de seus cotidianos em suas respectivas instituições de ensino. Neste sentido, ouvir jovens, saber o que pensam sobre as aulas práticas experimentais e as relações entre química e o dia-a-dia é uma ação rica do ponto de vista das informações que se podem ser obtidas.

Entendemos que o ensinar não pode ser reduzido à transmissão de conteúdos e a um conjunto de métodos e técnicas de ensino, pois este, para nós, implica vivência interativa, numa situação contextualizada e complexa, a qual requer uma grande tomada de decisão, uma mobilização de conhecimentos dentro da ação e uma modificação de decisões na sala de aula, conforme alertado por Altet (2001).

Os conteúdos discutidos nas aulas de Química permitem uma ampla quantidade de interações com as outras disciplinas do Ensino Médio, algumas discussões interdisciplinares podem ser causadas a partir de temas de grande relevância, tais como os problemas relacionados com a saúde e as questões ambientais. Conceitos como proteínas e sua ação enzimática são apresentados em momentos diferentes do Ensino Médio, durante as aulas de Química e Biologia.

Além disso, as discussões ressaltam somente os aspectos químicos ou biológicos, impedindo uma abordagem interdisciplinar que o enfoque bioquímico pode propiciar.

Assim, uma intervenção interdisciplinar explorando as proteínas como catalisadores planejada, aplicada e avaliada, pode facilitar tanto para os professores quanto para os alunos, pois facilita o entendimento dos alunos e, consequentemente, o processo de ensino-aprendizagem.

A adoção de uma abordagem interdisciplinar no Ensino Médio é uma das indicações dos documentos oficiais (Brasil, 1999) e pode ser considerada uma das maneiras de suplantar a fragmentação do conhecimento (Schinitman, 1987; Morin, 2002).

Além de impedir uma visão reducionista da Ciência, as intervenções interdisciplinares permitem utilizar assuntos mais interessantes para contextualizar as aulas favorecem a integração de conteúdos e expõem os alunos à complexidade do processo de geração do conhecimento.

\section{Metodologia}


A metodologia utilizada na pesquisa ocorreu de forma qualitativa e quantitativa, em dois momentos distintos. Durante duas manhãs (4 horas/aula) de atividades, 26 alunos da 2a série do Ensino Médio foram submetidos à intervenção interdisciplinar.

A ideia inicial era realizar um experimento em sala de aula, uma vez que mesmo o colégio possuindo laboratório, com vidrarias, materiais e reagentes, o mesmo não era utilizado pelo professor, pois segundo o mesmo "os alunos não são interessados".

Primeiramente, foi feita uma abordagem teórica sobre o assunto cinética química, com foco nos catalisadores. Em seguida aplicado um questionário com cinco questões abordando o assunto determinado.

\section{Exercícios}

\section{Questão 1}

Catalisador é toda substância que aumenta a taxa de desenvolvimento de determinadas reações químicas sem, contudo, participar dos produtos da reação, sendo integralmente recuperado no final, tanto em massa quanto na composição. Os catalisadores conseguem aumentar a velocidade das reações porque:

a. Com a presença do catalisador, a concentração aumenta, ou seja, aumenta o número de partículas por unidade de volume e, consequentemente, o número de choques efetivos será maior.

b. Com o catalisador, há mais choques efetivos, aumentando a energia cinética das partículas, aumentando a temperatura do sistema, que faz a reação se processar mais rápido.

c. O catalisador aumenta o número de partículas por unidade de volume e, consequentemente, a pressão aumenta, aumentando a taxa de desenvolvimento da reação.

d. O catalisador participa da formação do complexo ativado, fazendo com que os reagentes necessitem de uma energia de ativação menor para atingir esse estado, aumentando, dessa forma, a taxa de desenvolvimento da reação. (x)

e. O catalisador tem afinidade com todos os reagentes, ligando-se a todos eles e aumentando a velocidade com que eles se ligam.

\section{Questão 2}

(UMC-SP) Analise o gráfico de energia abaixo, obtido de uma mesma reação química. Uma 


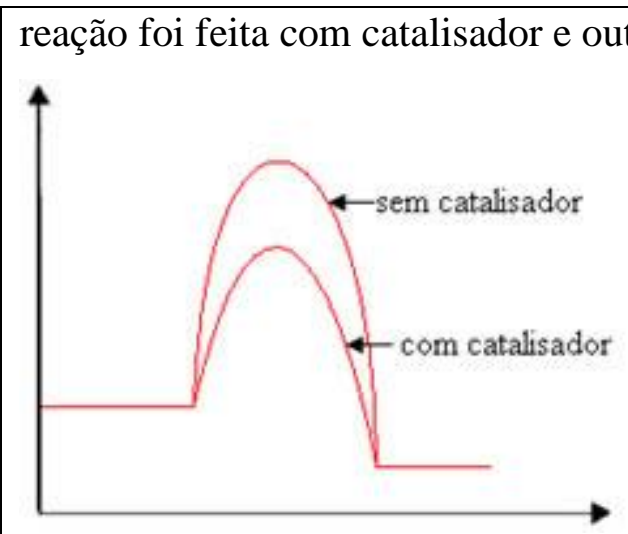

Assinale a afirmativa correta:

a. A reação é exotérmica devido ao catalisador empregado.

b. A entalpia da reação modificou-se devido ao emprego do catalisador.

c. A energia de ativação da reação diminuiu devido ao emprego do catalisador. (x)

d. A reação é endotérmica devido ao emprego do catalisador.

e. O catalisador não teve efeito algum na energia de ativação da reação.

\section{Questão 3}

(F.C. C) Um catalisador age sobre uma reação química:

a. Aumentando a energia de ativação da reação.

b. Diminuindo a energia de ativação da reação. (x)

C. Diminuindo a variação de entalpia da reação.

d. Aumentando o nível energético do produto.

e. Diminuindo o nível energético dos reagentes.

\section{Questão 4}

(UFMG) Na cinética de uma reação, o aumento da temperatura provoca aumento de todas as seguintes grandezas, exceto:
a. Velocidade média das moléculas.
b. Número de colisões entre as moléculas dos reagentes.
c. Energia de ativação. (x)
d. Velocidade da reação.
e. Energia do sistema.

\section{Questão 5}

(UFRGS) Sobre catalisadores, são feitas as quatro afirmações seguintes:

I. São substâncias que aumentam a velocidade de uma reação. 
II. Reduzem a energia de ativação da reação.

III. As reações nas quais atuam não ocorreriam nas suas ausências.

IV. Enzimas são catalisadores biológicos.

Dentre essas afirmações, estão corretas apenas:
a. I e II.
b. II e III.
c. I, II e IV. (x)
d. I, II e III.
e. II, III e IV.

Os conceitos químicos e biológicos necessários para a compreensão dos experimentos serão abordados e desta maneira, os conhecimentos disciplinares serão progressivamente integrados e os fatos observados nos experimentos serão interpretados sob o ponto de vista bioquímico.

A avaliação dessa intervenção interdisciplinar será realizada por meio de questionários e dos depoimentos espontâneos dos alunos.

Foram escolhidos dois procedimentos experimentais, onde foi levado em consideração o local da realização da atividade, e a realidade social em que a escola esta inserida. Sendo assim, os experimentos são de fácil acesso e baixo custo, podendo sofrer adaptações dos materiais.

Experimento I: Decomposição da água oxigenada com batata

Material e Reagentes:

- Tubo de ensaio

- Suporte de tubos de ensaio

- Proveta de $10 \mathrm{ml}$

- Água oxigenada 9\%

- Batata

- Faca

Procedimento:

- 1. Colocar um pouco de água oxigenada num tubo de ensaio. 
- 2. Cortar um pequeno pedaço de batata descascada.

- 3. Com o auxílio de uma espátula, adicionar o pequeno pedaço de batata.

- 4. Observar.

Experimento II: Vulcão de Levedura

Material necessário:

- Copos

- Pasta de modelagem

- Fermento em pó

- Água oxigenada

- Detergente

- Corante alimentar

Procedimentos:

1. Dissolva o fermento no interior do vulcão.

2. Coloque algumas gotas de detergente.

3. Coloque agora lentamente a água oxigenada e rapidamente obtém resultados.

\section{Resultados e Discussão}

Os experimentos propostos para iniciar as atividades tiveram o objetivo de expor os alunos ao caráter baseado na experiência. Apesar do pouco tempo de aula, onde que tivemos que, para realizar o experimento, fazer essa intervenção em dois dias, os resultados foram satisfatórios, os alunos participaram bastante da atividade prática e responderam muito bem aos exercícios.

Além de mudar o ambiente usualmente encontrado na sala de aula, foi possível utilizar equipamentos básicos de laboratório e discutir como se planeja um experimento.

Quanto aos resultados quantitativos, foram observados os dados referentes às respostas dadas pelos alunos 26 participantes da atividade. No primeiro momento, após a exposição teórica do conteúdo apenas 10 alunos, equivalente a $36 \%$ da turma acertou mais de $50 \%$ do questionário (3 questões ou mais). 
Já após a realização da prática 24 alunos (92 \%) conseguiram obter resultados satisfatórios, ou seja, acertaram 3 questões ou mais do mesmo questionário.

Os dados alcançados estão representados no seguinte gráfico:

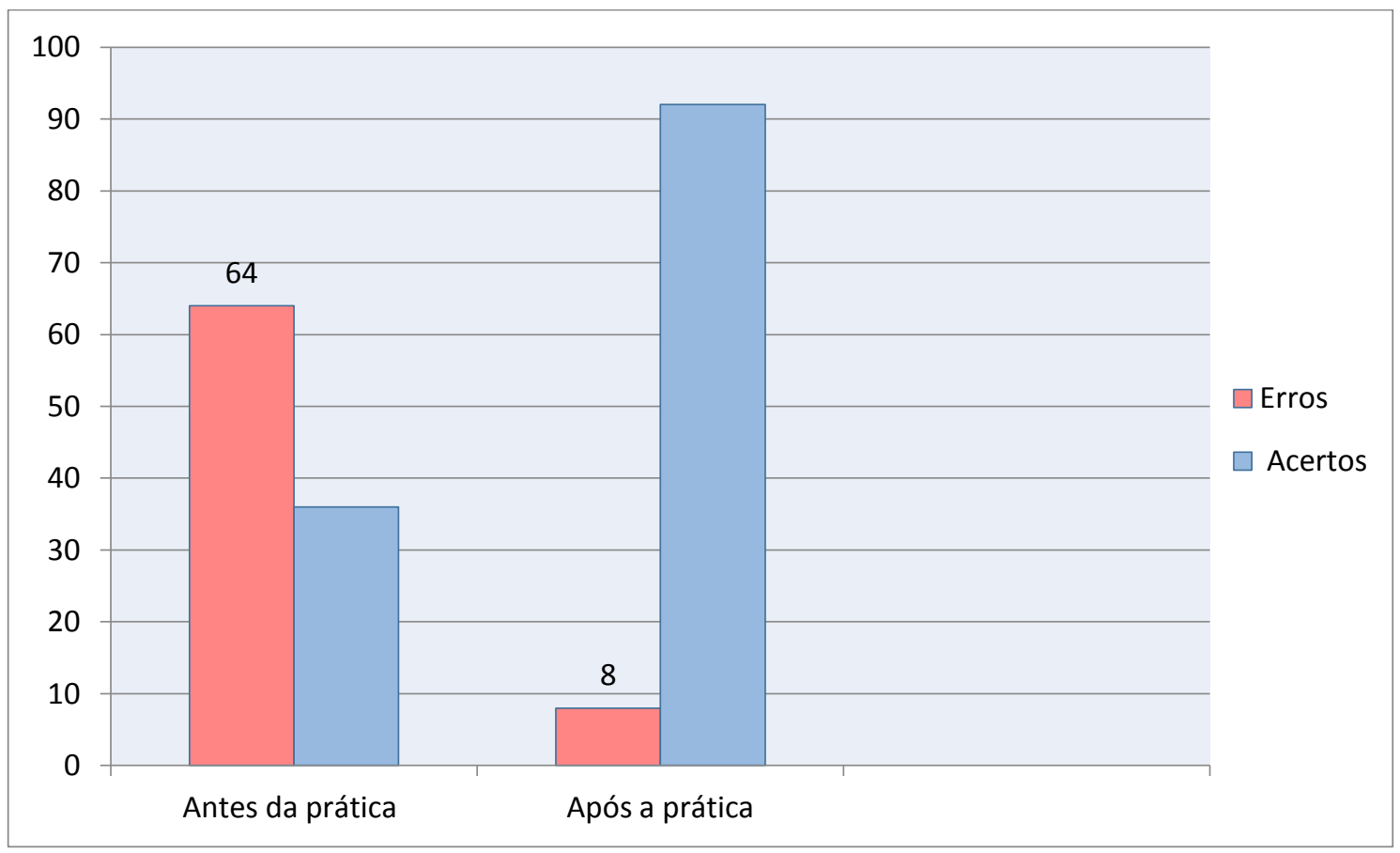

Gráfico 1: referentes as respostas dos alunos antes e após a prática

\section{Conclusões}

A disciplina de química no ensino médio deve utilizar de aulas práticas e amostragens, visando atrair o aluno e fazê-lo, através de interrogativas, promover uma investigação que atenda total ou parcialmente seus questionamentos, mesmo com respostas anteriores à explanação teórica. Busca-se o interesse dos mesmos através da curiosidade, com o interesse de formar cidadãos mais perspectivos, críticos e ativos.As formas alternativas de conhecimentos como práticas experimentais são de fundamental importância para aulas de química relacionando teoria e prática desenvolvendo assim uma aula de qualidade.

Durante a prática dos experimentos os alunos demonstravam grande interesse, que pôde ser percebido por constantes perguntas e hipóteses levantadas. Muitas perguntas eram feitas com exemplos que ocorriam em seu dia-dia e a cada pergunta respondida os alunos compreendiam a importância daquele experimento a importância da química na vida deles. Os alunos também relataram em conversas informais após a realização da atividade prática, a ausência de aulas experimentais na escola e, que se elas fossem realizadas com mais frequência, o aprendizado seria mais significativo. 
Estes experimentos forneceram, ainda, subsídio para que nós, futuros professores, sejamos capazes de mostrar, na prática o que os alunos aprenderam teoricamente sobre os conteúdos de cinética química/catalisador, e também para os que não compreenderam o assunto, possam mudar sua visão, já que eles estão vendo a reação acontecendo, e assim facilitando o aprendizado. Todos esses conteúdos foram abordados minuciosamente para que não houvesse dúvidas.

\section{Referências}

ALTET, Marguerite. As competências do professor profissional: entre conhecimentos, esquemas de ação e adaptação, saber analisar. PAQUAY, Léopoldet al. (org.) Formando professores profissionais: quais estratégias? Quais competências? Trad. Fátima Murad e Eunice Gruman. Porto A legre: Artmed, 2001, p. 23-35.

BRASIL. Parâmetros Curriculares Nacionais de Ensino Médio. Parte III: Ciências da Natureza, Matemática e suas tecnologias, 1999.

CASTRO, Amélia Domingues de; CARVAlHO, Anna Maria Pessoa de (orgs.). Ensinar a ensinar: didática para a escola fundamental e média. São Paulo: Pioneira Thomson Learning, 2002.

EVANGELISTA, O. Imagens e reflexões: na formação de professores. Disponível em http://www.sepex.ufsc.br/anais_5/trabalhos155.html. Acesso em 1 de janeiro de 2015.

FELTRE, R. Química Orgânica. 6a ed. São Paulo: Moderna, 2004. v. 3.

LIMA, J. F. L. PINA, M. S. L. BARBOSA, R. N. B. e JOFÍLI, Z. M. S. A contextualização no ensino de cinética química. Química Nova. N 11. Maio, 2000.

NOLASCO, S.M. Atividades interdisciplinares. Química Nova, v. 25, p. 502-504, 2002.

NOVAES, F. J. M. AGUIAR, D. L. M. BARRETO, M. B. e AFONSO, J. C. Atividades Experimentais Simples para o Entendimento de Conceitos de Cinética Enzimática: Solanum tuberosum - Uma Alternativa Versátil. Química Nova. Vol. 35, º 1, p. 27-33. Fevereiro, 2013.

REIS, M. Completamente Química: Química Orgânica. - São Paulo: FTD, 2001. 